\title{
High Grade B-Cell Lymphoma with MYC and BCL2 or BCL6 Rearrangements
}

National Cancer Institute

\section{Source}

National Cancer Institute. High Grade B-Cell Lymphoma with MYC and BCL2 or BCL6

Rearrangements. NCI Thesaurus. Code C125904.

A rare B-cell non-Hodgkin lymphoma that is characterized by the abnormal rearrangement of two genes, MYC gene and either BCL2 or BCL6 genes. Patients with this type of lymphoma usually respond poorly to standard treatments and have a poor prognosis. 